\title{
A Conceptual Review of the Demands of chronic care and the Preparedness of Nurses Trained with the General Nursing Council of Zambia Curriculum
}

\author{
${ }^{1}$ M. Kabinga, ${ }^{1}$ Banda S. S \\ ${ }^{1}$ University of Zambia, School of Medicine, Department of Medical Education Development
}

\section{INTRODUCTION}

Nursing care for the chronically ill has become very important due to the increase in chronic diseases. Chronic diseases are defined as those conditions that last for at least three months and are not self-limiting, . A more recent definition describes chronic illness as an illness that is permanent or lasts a long time, may get slowly worse over time, may lead to death, or may finally go away, may cause permanent changes to the body and will certainly affect the person's quality of life, . Chronic diseases currently account for over half of the global health burden, and are becoming a growing health challenge in developing countries ${ }^{4}$. Moreover, chronic diseases are now the major cause of death and disability worldwide, . In Zambia, the incidence of chronic illness has increased steadily over the last two decades 5 . HIV and AIDS, and its attendant malignancies such as cancer of the cervix, Kaposi's Sarcoma and co-morbid infections like tuberculosis are a leading culprit for increasing the chronic disease burden. In this research, HIV and AIDS will be used as an archetype of chronic disease because of its chronicity.

When the first cases of HIV and AIDS were reported, it was identified as an acute disease. However, the condition has been recharacterised as chronic disease due to the way individuals are afflicted. Many biological and social forces including

\section{Corresponding author:}

M. Kabinga

University of Zambia

School of Medicine

Department of Medical Education Development

Email: ckabinga2001@yahoo.com an increased understanding of HIV and its associated disease processes, advances in biomedical technology, and the expansion of health and social services has led to the reframing of HIV and AIDS from an acute to a chronic disease ${ }^{6}$. HIV and AIDS is lengthy and has slow disease process from the time it is diagnosed to the time one gets full blown AIDS. People who suffer from HIV and AIDS experience impairment in body structure and function, requires that a patient modify normal life, and also persists over a long period of time and as such, they require nursing care. People living with HIV and AIDS also suffer from stigma, emotional distress, and feelings of uncertainty as much as they have to adhere to complicated drug regimen ${ }^{6}$.

Increase in chronic disease burden demands that the healthcare workforce particularly the nurses who are leaders in chronic care ${ }^{7}$ are adequately prepared to care for the chronically ill. The inadequacy in the training of the nurses in chronic care nursing can result in the nurses expressing attitudes that are viewed by society as inappropriate. There are several factors that influence inadequate preparedness of nursing students and practicing nurses in the care of chronically ill patients.

Authorities assert that the nurses' training in caring for patients with chronic illness is very critical and it affects the effectiveness of the treatment ${ }^{8}$. In discourses to improve nurse effectiveness in the care of chronically ill patients two factors are often considered. The two factors considered key in the interaction of nurse training and care outcome for 
the chronically ill are 1) a deficient curriculum that fails to recognise chronic care nursing as a central component of nursing education ${ }^{9}$, and 2 ) The way theoretical and clinical training are conducted with regard the process of acquiring knowledge, skills and attitudes imperative for nursing care needs of the chronically ill $^{10}$. From a desk review of the General Nursing Council of Zambia Registered Nursing Curriculum, nursing care of the chronically ill is not adequately addressed and not emphasised in the curriculum. Traditionally, the prevailing models of nursing education emphasize an approach, which focuses on episodic care aimed at curing disease in individuals in an acute care setting ${ }^{9}$. WHO has also stated that the current healthcare workforce lacks 'training, education and skills set' required to manage the burgeoning numbers of people living with chronic disease $^{3}$. These aspects, which WHO noted as lacking in nursing education are not purposeful but emanate as a result of multifaceted challenges such as nursing curricula and the way chronic care is taught. This entails that there is a need to improve the way in which chronic care nursing is taught to nursing students as they prepare for this demanding and essential aspect of their practice.

\section{STATEMENT OF THE PROBLEM}

There is a significant increase of chronic disease especially HIV and AIDS in the world, in general, and in Zambia specifically which has caused untold suffering among people. This increase in chronic disease burden has a resultant demand on nurses to provide quality-nursing care that addresses the needs of the chronically ill. A possibility exists that the current nursing education is not preparing students adequately for care of the chronically ill. The mismatch in chronic care demand and the preparedness of the nurses to provide it may be due to a deficient curriculum and how the nurses acquire knowledge, skills and attitudes that are required to meet the needs of the chronically ill.

\section{PURPOSE OF THE STUDY}

The study will therefore analyse, in more detail, the deficiency that seem to exist between nurse curricula and nurse practices and explore chronic care models or approaches evident among Zambian General Nursing Council (GNC) final year nursing students and GNC trained practicing nurses. The study will also assess how they formulate these chronic care models or approaches. In order to do this, the study will seek to answer the following questions:

\section{RESEARCH QUESTIONS}

1. Are registered nurses, trained under the Zambian GNC Curriculum (2000) adequately prepared with the knowledge, skills and attitudes required to meet the needs of chronically ill patients, in general, and specifically patients with Acquired Immuno-Deficiency Syndrome (AIDS), the archetype chronic disease in Zambia?

2. What chronic care models or approaches are evident among Zambian GNC final year nursing students and GNC trained practicing nurses? How do the nurses formulate these chronic care models or approaches?

3. Does the GNC curriculum prepare nurses to formulate and implement the chronic care models in dealing with chronically ill patients?

\section{CONCEPTUAL FRAMEWORK}

In order to guide the study in retaining focus on what is doable and limiting it to specific theoretical considerations, the study will be guided by the constructivist theory as a philosophical grounding and the Corbin and Strauss Chronic Illness Trajectory Framework as a standard of chronic care.

\section{Constructivism as an Educational Philosophy}

The assumptions expounded by the constructivist movement concerning the nature of learning provide a potent and appropriate philosophical grounding for exploring how nursing students and practicing nurses generate and consolidate chronic care nursing models and approaches. Doolittle contends that in constructivism an individual constructs knowledge from one's experiences, mental structures, and beliefs that are used to interpret objects and events ${ }^{11}$. The theory involves the active creation and modification of thoughts, ideas, and understandings as a result of experiences that occur within a socio-cultural context like nursing practice. The learner constructs his/her own conceptualisations of nursing practice and finds his/her own solutions to problems that may arise. Learning from experience enhances autonomy of mastering autonomy and independence ${ }^{12}$ in ways that facilitate independence of implementing nursing theories.

As a philosophy of learning, constructivism can be traced from as far back as the eighteenth century by the work of Giambattista Vico who asserted that 
humans can understand only what they have themselves constructed ${ }^{13,14}$. The contribution of Vico was very significant as it laid a foundation for constructivism. Other theorists like John Dewey, Jean Piaget and Vygotsky developed the idea further. Piaget's contribution to constructivism combines descriptions of the internal processes and the internal motivation to learn ${ }^{15}$. Learning and construction of knowledge also involves learners constructing their own understanding of the world through their interactions with it.

Three important constructivist consideration are therefore, a) reflections on own experiences of care for the chronically ill, b) motivation for learning to care for the chronically ill effectively, and c) application of skills learned from other settings/ responsibilities to chronic care nursing ${ }^{16}$. Constructivism therefore is centered on the learner who actively engages in creating and modification of thoughts, ideas and understandings as they practice with chronically ill patients. It also involves social learning as it takes place in a socio-cultural context in which the patient is cared for. The learner learns autonomously and is therefore responsible for his/her own learning.

Constrictising his theory it can be argued that nursing stud can grasp concepts and ideas ${ }^{17}$ about care ne chronically ill that they cannot understand on their own with help from teachers both in the classroom and clinical area who are more advanced, and also by interacting with their patients. Teachers therefore play a very critical role in providing a conducive environment for their students. Students, however, learn by doing and not by listening. This is accomplished by hands-on approach where students are actually involved in caring for the chronically ill. In constructivism, the emphasis is on the knowledge, beliefs, and skills an individual brings to the experience of learning ${ }^{18}$. In nursing education different clinical settings constitute a major part of the learning context. What they learn in class may not become a reality until the context is changed to meaningful experiences in the clinical area. Learning by doing then becomes very important in care of the chronically ill.

\section{The Corbin and Strauss Chronic Illness Trajectory Framework}

The Corbin and Strauss Chronic Illness Trajectory Framework management is recognised as a middlerange explanatory nursing theory ${ }^{19}$ and is widely used to study different chronic diseases. Even though different models and professional standards of nursing practice provide guidance about care for patients with chronic illnesses ${ }^{8,7}$, the commonest utilised model is the Corbin and Strauss Chronic Illness Trajectory Framework ${ }^{18}$. Anselm Strauss and his colleagues started studying chronic illness in patients as early as $1960^{18}$. Following intensive work, the social scientists focused on the conceptualisation of managing and shaping the course of an illness ${ }^{18}$. Corbin and Strauss developed a chronic disease trajectory framework following over 30 years of interdisciplinary research on a variety of chronic illnesses ${ }^{19}$. The model has since been used to study nursing care of different chronic diseases such as cancer, trauma, diabetes mellitus and stroke among others (Dorsett, 1991; Walker, 1991; Burton, 2000; Halcomb and Davidson, 2005). According to Monahan et al a trajectory is defined as "a course of illness over time plus the actions taken by patients, families and health professionals to manage or shape the course" 18 . The trajectory of an illness can be managed by nurses who are usually in close contact with the patient when admitted to hospital.

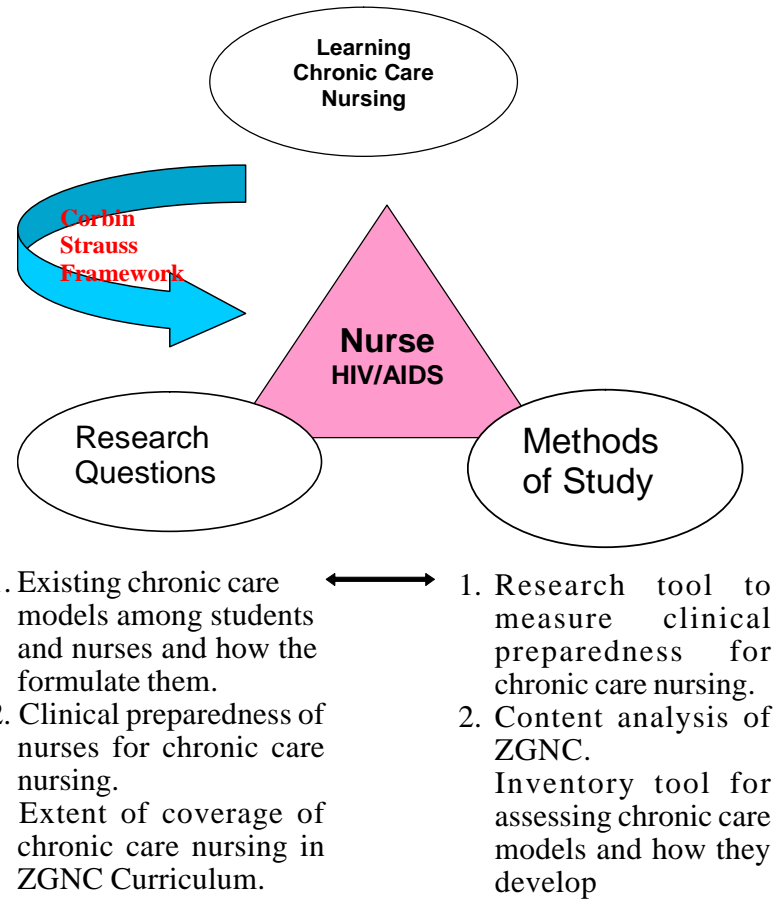


The Corbin and Strauss Chronic Illness Trajectory Framework consists of six steps: 1. Identifying the trajectory phase, 2 . Identifying problems and establishing goals, 3. Establishing plans to meet goals, 4. Identifying factors that facilitate or hinder attainment of goals, 5. Implementing interventions, and 6. Evaluating the effectiveness of interventions ${ }^{8}$. The strength of this trajectory model is the identification of differential phases in the course of a chronic disease, allowance for a variety of pathways in the disease trajectory and management strategies that a nurse can employ to shape the course of the illness.

Table 1: Steps in the Chronic Illness Trajectory Nursing Model Management

\begin{tabular}{|c|c|}
\hline $\begin{array}{l}\text { Steps in Chronic Illness } \\
\text { Trajectory Nursing Model }\end{array}$ & Nursing Care Involved \\
\hline $\begin{array}{l}\text { Step 1: Identifying the } \\
\text { Trajectory Phase }\end{array}$ & $\begin{array}{l}\text { Involves assessing the patient } \\
\text { and determining the specific } \\
\text { phase of trajectory } \\
\text { management. This assessment } \\
\text { enables the nurse to identify the } \\
\text { general management needed } \\
\text { because each management } \\
\text { phase has its own set of medical, } \\
\text { social, and psychological } \\
\text { problems. }\end{array}$ \\
\hline $\begin{array}{l}\text { Step 2: Identifying the } \\
\text { problems and establishing } \\
\text { goals. }\end{array}$ & $\begin{array}{l}\text { This step involves identifying } \\
\text { the specific problems } \\
\text { experienced by the patient } \\
\text { related to the phase of the } \\
\text { trajectory and establishing } \\
\text { goals. The problems and goals } \\
\text { and validated with the patient. }\end{array}$ \\
\hline $\begin{array}{l}\text { Step 3: Establishing plans to } \\
\text { meet the goals. }\end{array}$ & $\begin{array}{l}\text { This step consists of } \\
\text { establishing a realistic and } \\
\text { mutually agreed on plan for } \\
\text { reaching the goals. Specific } \\
\text { criteria to be used to assess } \\
\text { progress in meeting the goal } \\
\text { would also be identified. }\end{array}$ \\
\hline $\begin{array}{l}\text { Step 4: Identifying factors } \\
\text { that facilitate or hinder } \\
\text { attainment of goals. }\end{array}$ & $\begin{array}{l}\text { This step involves determining } \\
\text { factors that may interfere with } \\
\text { the achieving the goal(s). } \\
\text { Additionally, the nurse would } \\
\text { assist the person in identifying } \\
\text { resources that would decrease } \\
\text { the level of fatigue. }\end{array}$ \\
\hline $\begin{array}{l}\text { Step 5: Implementing } \\
\text { interventions. }\end{array}$ & $\begin{array}{l}\text { This step is the intervention } \\
\text { phase. Intervention can include } \\
\text { providing direct care or serving } \\
\text { as advocate for the patient, } \\
\text { teaching, counselling, making } \\
\text { referrals, or arranging for } \\
\text { resources or services. }\end{array}$ \\
\hline
\end{tabular}

Step 6: Evaluating the effectiveness of inventions

\section{IMPLICATIONS OF THE STUDY ON NURSING CURRICULA AND NURSING PRACTICES}

Knowledge of the nurses' implementation of the nurse education theory into practice provides insight to planners and nurse educators to design curricula and programmes on chronic care nursing that are effective. Nurse educators must be informed concerning required curricula reform and how to effectively prepare the future nursing workforce for care for the chronically ill patients.

\section{REFERENCES}

1. Hoffman C., Rice D., and Sung H. Y., (1996). Persons with Chronic Diseases, their Prevalence and Costs. Journal of the American Medical Association 276, 1473-1479.

2. Chronic Illness Alliance (2005). Http:// www.Chronic Illness Alliance Inc Home Page.htm. Accessed on $21^{\text {st }}$ October 2008.

3. WHO (2005). Preparing a Health Care Workforce for the $21^{\text {st }}$ Century: The Challenge of Chronic Conditions. World Health Organisation, Geneva.

4. Park S., (2003). Preventive and Social Medicine, Jaypee Brothers Medical Publishers, New Delhi.

5. Ministry of Health, (2005). Preventing Chronic Diseases. Government Printers, Lusaka.

6. Siegel K., and Lekas H.M., (2002). AIDS as a Chronic Illness: Psychosocial Implications. AIDS 2002, 16(suppl 4):S69-S76.

7. Bodenheimer, T, MacGregor, K., Nancy Stothart (2005), Nurses as Leaders in ChronicCare,BMJ330,(7492),612-613, http:// www.bmj.com/cgi/content/full/330/7492/612. Accessed on 28th September 2007.

8. Smeltzer S.C and Bare B. G., (1996), Brunner and Suddarth's Textbook of Medical-Surgical 
Nursing. Philadelphia, Lippincottt-Raven Publishers.

9. Astin F. and Closs, J.S., (2007). Guest Editorial: Chronic Diseases Management and Self-Care Support for People Living with Long term Conditions: Is the Nursing Workforce Prepared? Journal of Clinical Nursing 16 (7b), 105-106.

10. MacLeod R. D., Parkin C., Pullon S. and Robertson G., (2003). Early Clinical Exposure to People who are Dying: Learning to Care at the end of Life. Medical Education 2003; 37:51-58.

11. Doolittle P.E., and Hicks D., (2003). Constructivism as a Theoretical Foundation for the use of Technology in Social Studies. Theory and Research in Social Education, 31(1), 72104.

12. Thanasoulas D., (2002). Motivation and Motivating in the Foreign Language Classroom. Internet TESL Journal 8(11), November 2002.

13. Simon S. D., (1999). From Neo-Behaviourism to Social Constructivism?: The Paradigmatic Non-Evolution of Albert Bandura.
14. von Glasersfeld, (1995). Radical Constructivism: A Way of Knowing and Learning. London: Falmer.

15. Murphy E., (1997). Constructivist Epistemology. [Online] http://www.stemnetnf.ca/ elmurphy/ emurphy/cle2.html. Accessed on 21st October 2008.

16. Epstein M., (2002). Using Information effectively in Education. [Online] http:// tiger.towson.edu/ mepste $1 /$ research paper.htm Accessed on $21^{\text {st }}$ October 2008.

17. Cooley M., (1999). Analysis and Evaluation of the Trajectory Theory of Chronic Illness Management. Scholarly Inquiry for Nursing Practice: An International Journal, 13, 75109.

18. Phipps W.J, Monaham F.D, Sands J.K, Marek J.F and Neighbors M, (2003), Medical-Surgical Nursing, $7^{\text {th }}$ edition, Missouri, Mosby Inc. St. Louis.

19. Corbin J., and Strauss A. (1991a). A Nursing Model for Chronic Illness Management Based upon the Trajectory framework. Scholarly Inquiry for Nursing Practice, 5, 155-174. 